\title{
Efecto de diferentes dosis de estiércol bovino en el cultivo orgánico de Stevia rebaudiana (Bertoni) Bertoni bajo sistema de riego por goteo
}

\author{
Effect of different doses of bovine manure on Stevia rebaudiana (Bertoni) Bertoni \\ organic crop under drip irrigation system
}

\author{
José Augusto Velázquez Duarte ${ }^{1 *}$, Hugo Nicasio Rodríguez Espínola ${ }^{1}$, Marcos Arturo \\ Ferreira Agüero ${ }^{1}$, Gustavo Daniel Vega Britez ${ }^{1}$, Nelson David Lesmo Duarte ${ }^{1}$ y Jorge Dario \\ Alvarenga Serafini ${ }^{1}$
}

\author{
${ }^{1}$ Universidad Nacional de Asunción (UNA), Facultad de Ciencias Agrarias, Pedro Juan Caballero, Paraguay . \\ *Autor para correspondencia (joseaugusto05@hotmail.com) \\ Recibido: 07/06/2016; Aceptado: 16/08/2016. \\ 10.18004/investig.agrar.2016.dic ie mbre.101-110
}

\section{RESUMEN}

La producción de la Stevia "ka'a he'ẽ" es económicamente importante para la diversificación de la finca familiar. El objetivo de esta investigación fue evaluar los efectos de dosis de estiércol bovino $\left(0,20,40,60,80\right.$ y $\left.100 \mathrm{t} \mathrm{ha}^{-1}\right)$ en el cultivo de Stevia bajo irrigación. El diseño experimental adoptado fue el de bloques al azar con tres repeticiones, totalizando 18 unidades experimentales. Fueron determinados Masa Seca de Hojas (MSH) y Masa Seca de Tallos (MSt), Masa Seca Total (MST) por planta, distribución de asimilados en MSH, MST y rendimiento de MST por hectárea. Los resultados indican que con $60 \mathrm{t}$ $\mathrm{ha}^{-1}$ de estiércol bovino se obtuvo la mayor producción de MSH de Stevia por planta en el primer, segundo corte y total con 24,90;29,39 y 54,30 $\mathrm{g} \mathrm{pl}^{-1}$ respectivamente. En tallos se registraron 8,96; 12,01 y 20,97 $\mathrm{g} \mathrm{pl}^{-1} \mathrm{de}$ MSt. También se verifico que el rendimiento es influenciado por las dosis de estiércol bovino con: 2760,83; 2521,66 y $5282,50 \mathrm{~kg} \mathrm{ha}^{-1}$ de MSH, MSt y MST para el primer y segundo corte, $y$ en forma total siendo la dosis de $60 \mathrm{t} \mathrm{ha}^{-1}$ el que arrojó mejores resultados. No se detectó la influencia de las dosis de estiércol en la distribución de asimilados en el primer corte con $73,88 \%$ a las hojas y $26,10 \%$ a los tallos. Ya en el segundo corte se verificó efecto significativo con la dosis de 100,0 $\mathrm{t} \mathrm{ha}^{-1}$ de estiércol con una media de 78,32\%, distribuyendo la mayor cantidad de MS a las hojas. Estas informaciones son útiles para recomendar dosis de estiércol bovino en Stevia.

Palabras claves: Stevia rebaudiana (Bertoni) Bertoni, producción, fertilización orgánica, mas a seca, asimilados.

\begin{abstract}
Stevia production is economically important for diversification of family farms. The aim of this research was the assessment of the effect of different bovine manure doses $(0,20,40,60,80$ and $100 \mathrm{t}$ ha-1) on stevia grown under irrigation. The experimental design was randomized block with three replicates and eighteen experimental units. Leaf Dry Mass (LDM), Stems Dry Mass (SDM) and Total Dry Mass (TDM) per plant were determined as well as assimilate distribution in LDM, SDM and SDM yield per hectare. Results showed that with $60 \mathrm{t}$ ha-1 of bovine manure was obtained the highest LDM per plant in the first cut, the second cut and a total with $24.90 ; 29.39$ and $54.30 \mathrm{~g}$ pl-1 respectively. On stems, 8.96; 12.01 and $20.97 \mathrm{~g}$ pl-1of SDM were recorded. It was also established that yield is influenced by doses of bovine manure with $2760.83 ; 2521.66$ and $5282.50 \mathrm{~kg}$ ha-1 of LDM, SDM and TDM in the first cut, the second cut and the total, respectively, being the $60 \mathrm{t}$ ha-1 of bovine manure the dose with the best result. It was not detected any influence of manure dose on assimilate distribution in the first cutting $73.88 \%$ for leaves and $26.10 \%$ for stems. On the second cut, a significant effect was verified when applying $100.0 \mathrm{t}$ halof bovine manure and with an average of $78.32 \%$, allocating the highest quantity of DM to leaves. This information is useful to recommend doses of bovine manure for stevia production.
\end{abstract}

Key words: Stevia rebaudiana, production, organic fertilization, dry matter, assimilated. 


\section{INTRODUCCIÓN}

La Stevia rebaudiana (Bertoni) Bertoni es una hierba perenne, Asterácea. Crece en forma silvestre en el noroeste de Paraguay y suroeste de Brasil, conocida con el nombre de ka'a he'ê en guaraní cuyo significado es yerba dulce (Serfaty et al. 2013). El Paraguay, específicamente en el Departamento de Amambay por ser centro de origen de esta planta posee regiones con características edafoclimáticas óptimas para su producción.

El atractivo mercado de la Stevia es creciente a nivel mundial, países desarrollados como Japón e Israel la utilizan desde hace más de 40 años. El nivel de consumo en el Japón alcanza el $60 \%$ de su población, motivando a grandes empresas utilizarla. Egipto, Gran Bretaña, Arabia Saudita e Israel entre otros, desarrollan productos y endulzante natural, que además, de sus usos medicinales y alimenticios son de interés para la industria cosmética (López y Peña 2004).

La Stevia por ser bajo en calorías es el fármaco potencial adecuado para los diabéticos (Yong-Heng et al. 2014). Se ha utilizado en el tratamiento de la obesidad y la hipertensión arterial, mejorando así la calidad de vida de las personas que padecen estas enfermedades (Mejía 2009).

En el Paraguay, la Stevia es uno de los rubros fomentados por el Ministerio de Agricultura y Ganadería dentro del programa de diversificación, concentrándose la producción en los Departamentos de San Pedro (240 ha) y Concepción (300 ha) prioritariamente, aunque se está promoviendo el cultivo a otros Departamentos como Amambay (Duarte 2008). Su producción por mano de obra familiar a nivel nacional para consumo o como rubro de renta en el mercado internacional en forma de edulcorante en sustitución de la sacarosa ha despertado gran interés (Casaccia y Álvarez 2006).

Según Lozano y Ramírez (2015) los abonos orgánicos que pueden ser utilizados para la producción de Stevia son la gallinaza, bokashi o estiércol bovino, los cuales se deben incorporar al suelo antes de realizar el acolchado de las camas, a una dosis de $2 \mathrm{t} \mathrm{ha}^{-1}$ para suelos mexicanos. Por otro lado, en Paraguay se recomienda aplicar entre 30 a $40 \mathrm{t} \mathrm{ha}^{-1}$ de estiércol bovino para suelos con bajo contenido de materia orgánica (Casaccia y Álvarez 2006). La aplicación del mismo debe realizarse durante las labores de preparación del terreno. La influencia de la materia orgánica sobre las propiedades del suelo no es solo en el aspecto nutricional, sino que también ejerce efectos positivos en cuanto a la retención de humedad y manutención de la temperatura del suelo, en crear un poder 'buffer' en la solución del suelo con condiciones ideales para el desarrollo de microorganismos.

También la limitada profundidad y la escasa expansión alcanzada por el sistema radicular, así como la naturaleza herbácea y el ritmo de crecimiento de la Stevia, exige que el suelo tenga un adecuado nivel de humedad para asegurar el buen desarrollo de las plantas. En cultivos establecidos en zonas donde la precipitación anual es inferior a los $1.400 \mathrm{~mm}$, en general es recomendable la utilización de sistemas de irrigación, la necesidad hídrica del cultivo es de $5 \mathrm{~mm}$ diarios aplicados con intervalos de tres días, si el suelo es del tipo arenoso y cada cinco días si es ligeramente arcilloso. El riego se debe suspender 15 días antes de la cosecha, de manera a no afectar el tenor de glucósidos en la hoja (Casaccia y Álvarez 2006).

Los suelos donde son cultivadas la Stevia, si presentan bajo contenido de materia orgánica pueden repercutir negativamente en el rendimiento, teniendo en cuen ta que la parte comercializada es la hoja y que el aumento en masa foliar responde positivamente a la fertilización orgánica en el suelo. Como es un cultivo que se desarrolla normalmente en pequeñas fincas con áreas menores a 2 ha, una forma rápida de incorporar materia orgánica al suelo es mediante la aplicación de estiércol bovino, material que, por lo general, está disponible en forma abundante en la finca del productor. Debido a la escasez de trabajos sobre el efecto de aplicación de estiércol bovino en el cultivo de Stevia, este trabajo tuvo como objetivo evaluar el efecto de diferentes dosis de estiércol bovino en la producción de Stevia bajo sistema de riego por goteo.

\section{MATERIALES Y MÉTODOS}

El estudio fue realizado en la ciudad de Pedro Juan Caballero, a la altura del km 2 de la Ruta V "General Bernardino Caballero", ubicada entre las coordenadas geográficas latitud $22^{\circ} 57^{\prime} 35^{\prime}$ ', longitud $55^{\circ} 73^{\prime} 48^{\prime}$ ' y altitud $619 \mathrm{msnm}$. Durante los meses de diciembre de 2007 a junio de 2008. El clima se caracteriza por ser mesotérmico, y su temperatura media anual es una de las más bajas del Paraguay, con valores entre 21 y $23^{\circ} \mathrm{C}$. Las precipitaciones alcanzan $1.700 \mathrm{~mm}$ anuales y los meses más lluviosos son enero, febrero y marzo (DINAC 2012).

El suelo con características de textura arcillosa, ligeramente ácido, nivel de materia orgánica bajo, nivel 
de fósforo bajo, nivel de potasio medio, de acuerdo con los resultados del análisis de suelo realizado en el Laboratorio de Suelos de la Facultad de Ciencias Agrarias de la filial Pedro Juan Caballero, conforme la Tabla 1 donde se detallan las principales características físicoquímicas.

Tabla 1. Resultado del análisis de suelo realizado en el Laboratorio de Suelos de la Facultad de Ciencias Agrarias, Sede Pedro Juan Caballero. Pedro Juan Caballero, Paraguay.

\begin{tabular}{ccccccc}
\hline $\mathrm{pH}$ & $\mathrm{M} . \mathrm{O}$. & $\mathrm{P}$ & $\mathrm{K}^{+}$ & $\mathrm{Ca}^{+2}+\mathrm{Mg}^{+2}$ & $\mathrm{Al}^{+3}$ & Textura \\
\cline { 2 - 6 } & $\mathrm{dag} \cdot \mathrm{kg}^{-1}$ & $\mathrm{Mg}$ & $\mathrm{kg}^{-1}$ & $\mathrm{Cmol}_{\mathrm{kg}}{ }^{-1}$ & & \\
\hline 6,10 & 0,80 & 10,47 & 0,14 & 1,7 & 0,00 & Arcillosa \\
\hline
\end{tabular}

Los tratamientos consistieron en la aplicación de seis diferentes dosis de estiércol bovino $(0,20,40,60,80 \mathrm{y}$ $100 \mathrm{t} \mathrm{ha}^{-1}$ ) en un diseño experimental de bloques al azar con tres repeticiones. La unidad experimental consistió en parcelas de $4 \mathrm{~m}^{2}$, y los tratamientos fueron aplicados 15 días antes del trasplante de los plantines de Stevia variedad Eireté provenientes de viveros de propagación vegetativa del municipio de Horqueta, Departamento de Concepción, Paraguay.

La preparación del suelo fue realizada de forma mecanizada con motocultivador en dos pasadas, a una profundidad entre 15 a $20 \mathrm{~cm}$. La aplicación del estiércol bovino se realizó con la apertura de un surco de $25 \mathrm{~cm}$ de ancho y $10 \mathrm{~cm}$ de profundidad y mezclada con el suelo.

El trasplante se realizó en la primera quincena de diciembre de 2007, con un espaciamiento de $50 \mathrm{~cm}$ entre hileras y $20 \mathrm{~cm}$ entre plantas, obteniendo una densidad de 100.000 plantas $\mathrm{ha}^{-1}$. Inmediatamente después del trasplante las parcelas fueron irrigadas utilizando un sistema de riego por goteo, con una exposición diaria durante 20 minutos en dos oportunidades (mañana y tarde), con interrupción en los días de lluvia. A cada hilera de plantas le correspondió una línea de goteo, y un goteador por planta, con un caudal de $0,7 \mathrm{~L} \mathrm{~h}^{-1}$.

El control de malezas se realizó en forma manual, el primero efectuado 10 días después del corte de uniformización, el segundo a los 25 días de la primera limpieza, el tercero 30 días antes del primer corte de evaluación y el cuarto 30 días después del primer corte. No se aplicó ningún producto químico para insectos plagas ni enfermedades, considerándose que el cultivo fue realizado en forma orgánica.

El corte de uniformización fue efectuado a los 30 días después del trasplante, y los cortes de evaluación se efectuaron en dos oportunidades: abril y junio de 2008. Los efectos de los tratamientos fueron evaluados mediante los siguientes caracteres de interés agronómico: masa seca de hojas y tallos por planta $\left(\mathrm{g} \mathrm{pl}^{-1}\right)$, masa seca total por planta $\left(\mathrm{g} \mathrm{pl}^{-1}\right)$, rendimiento en masa seca total $\left(\mathrm{kg} \mathrm{ha}^{-1}\right)$ y distribución de asimilados por planta (\%), por corte $\left(1^{\circ}\right.$ y $\left.2^{\circ}\right)$ y en forma total. Para la masa seca de hojas y tallos por planta fueron elegidas al azar cuatro plantas con competencia perfecta en cada unidad experimental (UE), siendo empleadas las mismas plantas en los dos cortes efectuados.

El corte se realizó a $2 \mathrm{~cm}$ del suelo, separándose las hojas y tallos de cada planta y secándose a la sombra durante dos días sobre papel blanco, evitando encimar las hojas de manera a impedir el deterioro por hongos y pérdida de la calidad de la hoja. Luego, cada fracción fue pesada por separado en una balanza electrónica de $0,01 \mathrm{~g}$ de resolución y los valores medios de las cuatro plantas representaron a cada UE, expresándose los valores en $\mathrm{g}$ $\mathrm{pl}^{-1}$. La sumatoria de la masa seca de hojas y tallos correspondió a la masa seca total por planta. El rendimiento en masa seca total fue obtenido mediante el corte total de todas las plantas de cada unidad experimental, separándose en fracción hoja y fracción tallo, y pesándose en una balanza electrónica de $0,01 \mathrm{~g}$ de resolución y extrapolando los valores para 1 ha dándose en $\mathrm{kg} \mathrm{ha}^{-1}$.

La distribución de asimilados fue calculada mediante:

AH $=($ MSHojas $/$ MSTotal $) \times 100$

AT $=($ MSTallos/MSTotal $) \times 100$

dónde:

AH: $\quad$ Asimilados en hojas (\%)

AT: $\quad$ Asimilados en tallos (\%)

MSHojas: $\quad$ Masa seca de hojas $\left(\mathrm{g} \mathrm{pl}^{-1}\right)$

MStallos: $\quad$ Masa seca de tallos $\left(\mathrm{g} \mathrm{pl}^{-1}\right)$

MSTotal: $\quad$ Masa seca total de la parte aérea $\left(\mathrm{g} \mathrm{pl}^{-1}\right)$

Los datos obtenidos fueron sometidos a análisis de varianza mediante el Test de Fisher al 5\% y las medias comparadas entre sí por el Test de Duncan al $5 \%$. 
También se efectuó análisis de regresión de manera a ajustar curvas entre las dosis de estiércol bovino aplicados y cada una de las determinaciones efectuadas, y, en caso de que corresponda, calcular el punto de máxima eficiencia técnica. Para todos los análisis estadísticos se utilizó el paquete estadístico ESTAT 2.0.

\section{RESULTADOS Y DISCUSIÓN}

De las dosis de estiércol bovino evaluadas (0, 20, 40, 60, 80 y $100 \mathrm{t} \mathrm{ha}^{-1}$ ), se ha verificado resultados significativos para el nivel de $60 \mathrm{t} \mathrm{ha}^{-1}$ en relación a la producción de masa seca de hojas (MSH) de Stevia. La producción de
MSH en el primer corte $\left(24,90 \mathrm{~g} \mathrm{pl}^{-1}\right)$, segundo corte $\left(29,34 \mathrm{~g} \mathrm{pl}^{-1}\right)$, y total $\left(54,30 \mathrm{~g} \mathrm{pl}^{-1}\right)$, observada con esa dosis de estiércol fue significativamente superior a los observados en el testigo (sin aplicación) y los demás tratamientos: 20, 40, 80 y $100 \mathrm{t} \mathrm{ha}^{-1}$ (Tabla 2).

En estudios similares realizados en Israel en el cultivo de Stevia bajo irrigación con sistema de goteo y fertilización química nitrogenada, la producción de MSH por planta fue de $8,75 \mathrm{~g} \mathrm{pl}^{-1}$ en septiembre, que luego fue decreciendo en agosto y octubre a $6,25 \mathrm{~g} \mathrm{pl}^{-1}$ (Serfaty 2013). Estos valores comparativamente a los obtenidos en este estudio son inferiores.

Tabla 2. Medias de producción de masa seca de hojas de Stevia por planta $\left(\mathrm{g} \mathrm{pl}^{-1}\right)$ por efecto de los tratamientos. Pedro Juan Caballero, Paraguay.

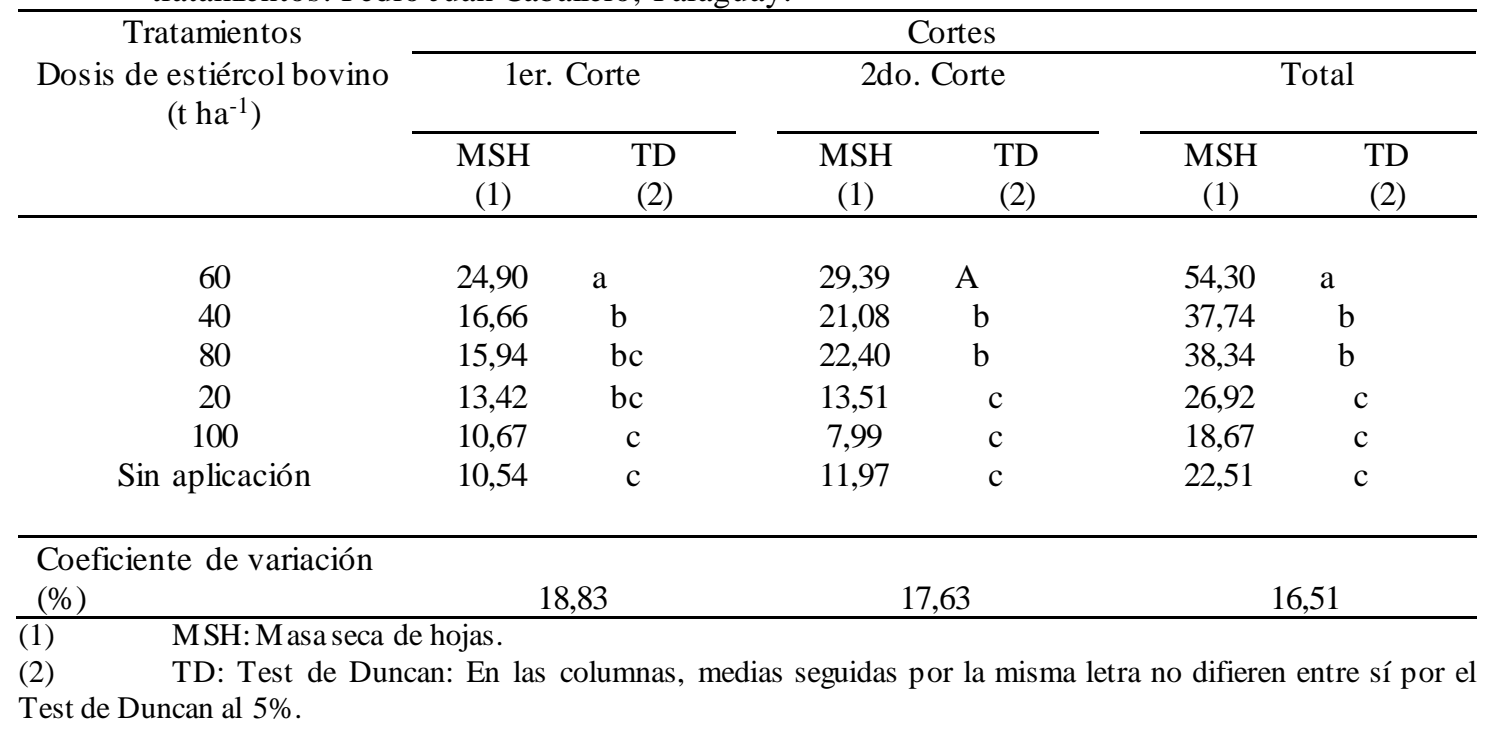

En todos los casos fue verificado un efecto cuadrático de las dosis de estiércol bovino evaluados hasta un nivel crítico, por encima del cual ya se produjo una reducción en la acumulación de masa seca de hojas (MSH) por planta (Figura 1). Considerando los valores críticos verificados para cada curva, la dosis óptima de estiércol bovino estimada por el análisis de regresión para este cultivo fue de $52 \mathrm{t} \mathrm{ha}^{-1}$ considerando el punto de máxima eficiencia técnica. Este resultado demuestra que dosis menores $\left(20\right.$ y $\left.40 \mathrm{t} \mathrm{ha}^{-1}\right)$ resultan en menor producción de masa seca de hojas así como dosis mayores $\left(80 \mathrm{t} \mathrm{ha}^{-1}\right)$ incluso con la mayor dosis experimentada de $100 \mathrm{t} \mathrm{ha}^{-1}$, la producción fue similar al del testigo (sin aplicación) evidenciando de esta forma que altas dosis también pueden perjudicar a la producción de masa seca de hojas de Stevia.
Estudios realizados por Liu et al. (2011) demuestran que el abono orgánico en la forma de estiércol bovino proporciona mayor actividad radicular, mejorando la fotosíntesis en etapa de crecimiento con consecuente incremento en la biomasa (MS) y contenido de glucósidos de la Stevia, incluso el crecimiento, diámetro y altura de tallo, así como el peso seco de la parte aérea fue superior al cultivo de Stevia tratado con fertilizante químico. El resultado obtenido en este estudio como la mejor dosis (52 $\mathrm{t} \mathrm{ha}^{-1}$ ) es superior al obtenido por Encina (2008), quien menciona que la dosis de estiércol bovino indicado para el cultivo de Stevia estaría entre 30 a $40 \mathrm{t} \mathrm{ha}^{-1}$ para suelos con bajo contenido de materia orgánica.

Los datos presentados en la Tabla 3 se refieren a las medias de la masa seca de tallos (MSt) por planta $\left(\mathrm{g} \mathrm{pl}^{-1}\right)$ en cada uno de los cortes realizados y en forma total. Se verificó efecto significativo de los tratamientos en ambos cortes y en el total (primer + segundo corte) sobre este 
carácter, de acuerdo con el Test de Fisher al 5\%. En el primer corte, las plantas provenientes del tratamiento con $60 \mathrm{t} \mathrm{ha}^{-1}$ fueron significativamente superiores en relación a la MSt obtenidas en comparación con las demás dosis de estiércol bovino (Test de Duncan al 5\%), con una media de $8,96 \mathrm{~g} \mathrm{pl}^{-1}$, seguidas por las de los tratamientos 40 y $80 \mathrm{t} \mathrm{ha}^{-1}$ con un promedio de $6,06 \mathrm{~g} \mathrm{pl}^{-1}$, y en último lugar se posicionaron las plantas de Stevia provenientes del tratamiento de $100 \mathrm{t} \mathrm{ha}^{-1} \mathrm{y}$ el testigo sin aplicación de estiércol bovino que produjo apenas 3,21 $\mathrm{g} \mathrm{pl}^{-1} \mathrm{de} \mathrm{MSt}$.
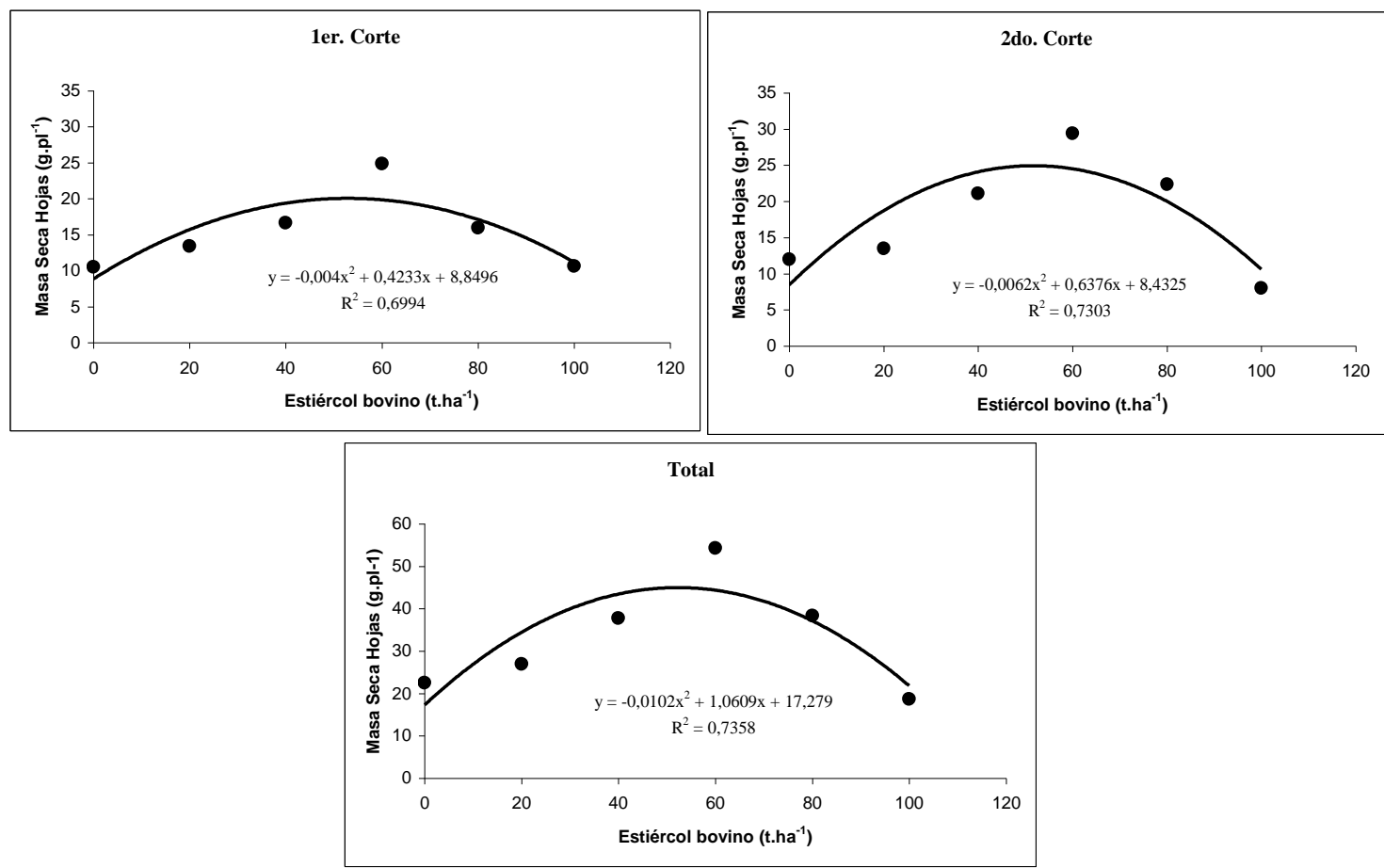

Figura 1. Curvas ajustadas entre las medias de la masa seca de hojas de Stevia por planta $\left(\mathrm{g} \mathrm{pl}^{-1}\right)$ y las dosis de estiércol bovino aplicadas. Pedro Juan Caballero, Paraguay.

Tabla 3. Medias de la masa seca de tallos de Stevia por planta $\left(\mathrm{g} \mathrm{pl}^{-1}\right)$ por efecto de los tratamientos. Pedro Juan Caballero, Paraguay.

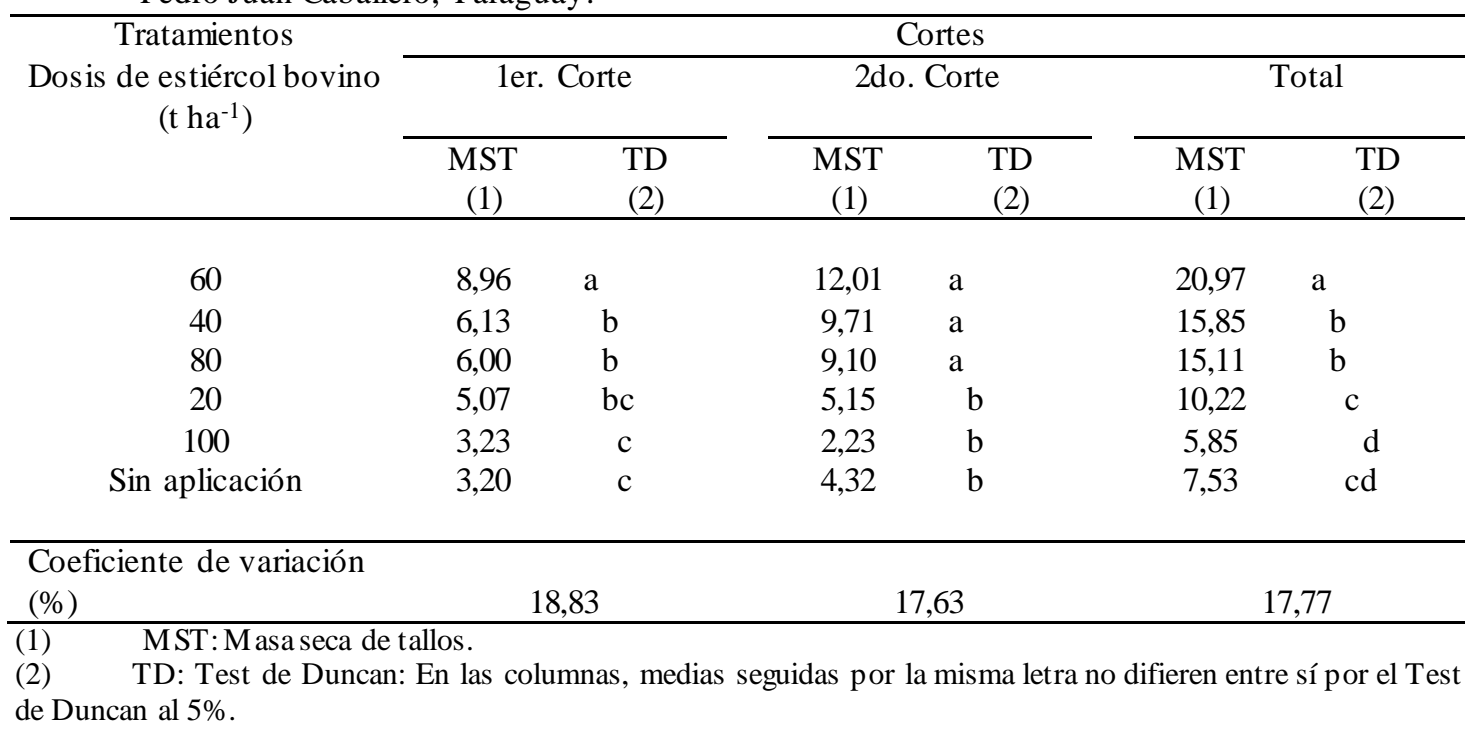

Por otro lado, el tratamiento con $60 \mathrm{t} \mathrm{ha}^{-1}$ de estiércol bovino produjo un efecto de $47,85 \%$ mayor que los

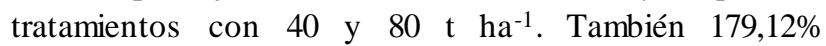

superior que el tratamiento con $100 \mathrm{t} \mathrm{ha}^{-1} \mathrm{y}$ testigo en la producción de MSt por planta en el primer corte. Para el segundo corte, las dosis de estiércol bovino 
correspondientes a 60,40 y $80 \quad \mathrm{t} \quad \mathrm{ha}^{-1}$ fueron estadísticamente similares entre sí según los resultados del test de Duncan al 5\%, con un promedio de 10,27 $\mathrm{g} \mathrm{pl}^{-1}$ de MSt, superando en 163,33\% a las plantas de Stevia provenientes de los tratamientos con 20 y $100 \mathrm{t} \mathrm{ha}^{-1} \mathrm{de}$ estiércol bovino y testigo, que en promedio apenas lograron producir 3,9 $\mathrm{g} \mathrm{pl}^{-1}$ de MSt.
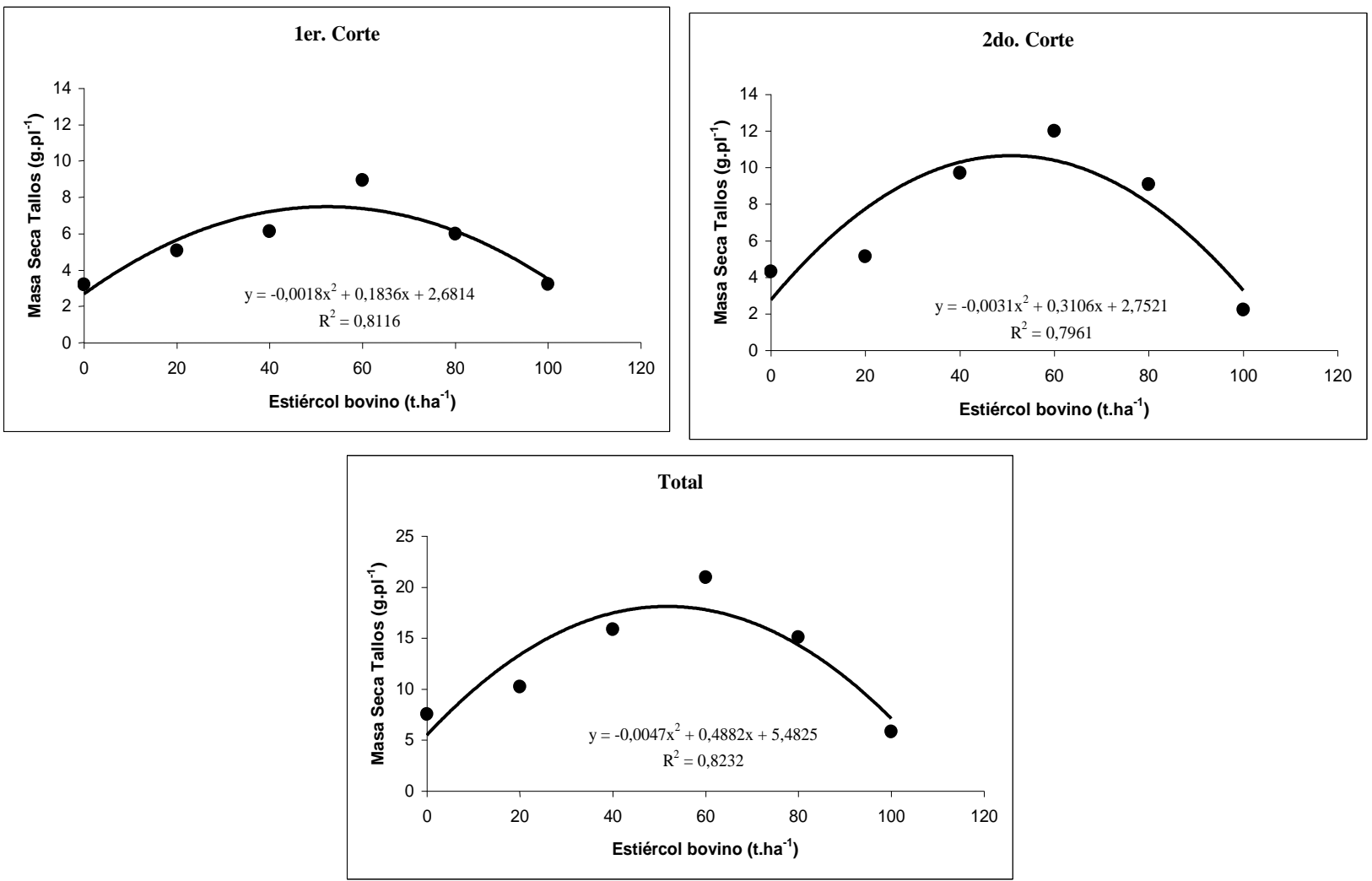

Figura 2. Curvas ajustadas entre las medias de la masa seca de tallos de Stevia por planta $\left(\mathrm{g} \mathrm{pl}^{-1}\right)$ y las dosis de estiércol bovino aplicadas. Pedro Juan Caballero, Paraguay.

La figura 2 permite verificar que existe un efecto creciente de las dosis de estiércol bovino aplicados hasta un límite por encima del cual se observa una reducción en la acumulación de MSt por planta. En el primer corte el valor crítico de máxima eficiencia técnica del estiércol bovino corresponde a $51 \mathrm{t}$ ha-1, en el segundo corte a $50,09 \mathrm{t}$ ha-1 y en forma combinada a $51,93 \mathrm{t}$ ha- 1 , con valores teóricos de 7,36; 10,53 y 18,16 g pl-1, respectivamente.

Las medias de la masa seca total (MST) de Stevia por planta en cada uno de los cortes y en forma conjunta son presentadas en la Tabla 4. En todos los casos se verificó que las plantas que recibieron la aplicación de $60 \mathrm{t} \mathrm{ha}^{-1}$ acumularon mayor masa seca total (MST) por planta $\left(33,86 \mathrm{~g} \mathrm{pl}^{-1}\right)$ en el primer corte, $41,41 \mathrm{~g} \mathrm{pl}^{-1}$ en el segundo corte y $75,27 \mathrm{~g} \mathrm{pl}^{-1}$ en forma total), estadísticamente superiores a los demás tratamientos.

Estas ecuaciones de regresión (Figura 3) permiten verificar que existe un efecto creciente sobre la masa seca total (MST) de Stevia por planta con el aumento de las dosis de estiércol bovino hasta un punto crítico por encima del cual este carácter comienza a decrecer.

Los valores críticos de máxima eficiencia técnica del estiércol bovino para la MST por planta de Stevia corresponden a 52,$71 ; 51,53$ y $51,98 \mathrm{t} \mathrm{ha}^{-1}$, con los que se alcanzarían 27,41; 35,61 y 63,02 $\mathrm{g} \mathrm{pl}^{-1}$ de masa seca total (MST). 
Tabla 4. Medias de la masa seca total de Stevia por planta $\left(\mathrm{g} \mathrm{pl}^{-1}\right)$ por efecto de los tratamientos. Pedro Juan Caballero, Paraguay.

\begin{tabular}{|c|c|c|c|c|c|c|}
\hline \multirow{3}{*}{$\begin{array}{c}\text { Tratamientos } \\
\text { Dosis de estiércol bovino } \\
\left(\mathrm{t} \mathrm{ha}^{-1}\right)\end{array}$} & \multicolumn{6}{|c|}{ Cortes } \\
\hline & \multicolumn{2}{|c|}{ 1er. Corte } & \multicolumn{2}{|c|}{ 2do. Corte } & \multicolumn{2}{|r|}{ Total } \\
\hline & $\begin{array}{c}\text { MST } \\
(1)\end{array}$ & $\begin{array}{l}\text { TD } \\
(2)\end{array}$ & $\begin{array}{c}\text { MST } \\
(1)\end{array}$ & $\begin{array}{l}\mathrm{TD} \\
\text { (2) }\end{array}$ & $\begin{array}{l}\text { MST } \\
(1)\end{array}$ & $\begin{array}{l}\mathrm{TD} \\
(2)\end{array}$ \\
\hline 60 & 33,86 & $\mathrm{a}$ & 41,41 & $\mathrm{a}$ & 75,27 & $\mathrm{a}$ \\
\hline 40 & 22,80 & $\mathrm{~b}$ & 30,79 & b & 53,59 & $\mathrm{~b}$ \\
\hline 80 & 21,95 & $\mathrm{~b}$ & 31,50 & $\mathrm{~b}$ & 53,45 & $\mathrm{~b}$ \\
\hline 20 & 18,48 & bc & 18,66 & $\mathrm{c}$ & 37,15 & $\mathrm{c}$ \\
\hline Sin aplicación & 13,75 & $\mathrm{c}$ & 16,29 & $\mathrm{~cd}$ & 30,04 & $\mathrm{~cd}$ \\
\hline 100 & 14,29 & $\mathrm{c}$ & 10,23 & $\mathrm{~d}$ & 24,52 & $\mathrm{~d}$ \\
\hline $\begin{array}{l}\text { Coeficiente de variación } \\
(\%)\end{array}$ & \multicolumn{2}{|c|}{19,54} & \multicolumn{2}{|c|}{17,63} & \multicolumn{2}{|r|}{17,77} \\
\hline
\end{tabular}

(1) MST: Masa seca total.

(2) TD: Test de Duncan: En las columnas, medias seguidas por la misma letra no difieren entre sí por el Test de Duncan al $5 \%$.
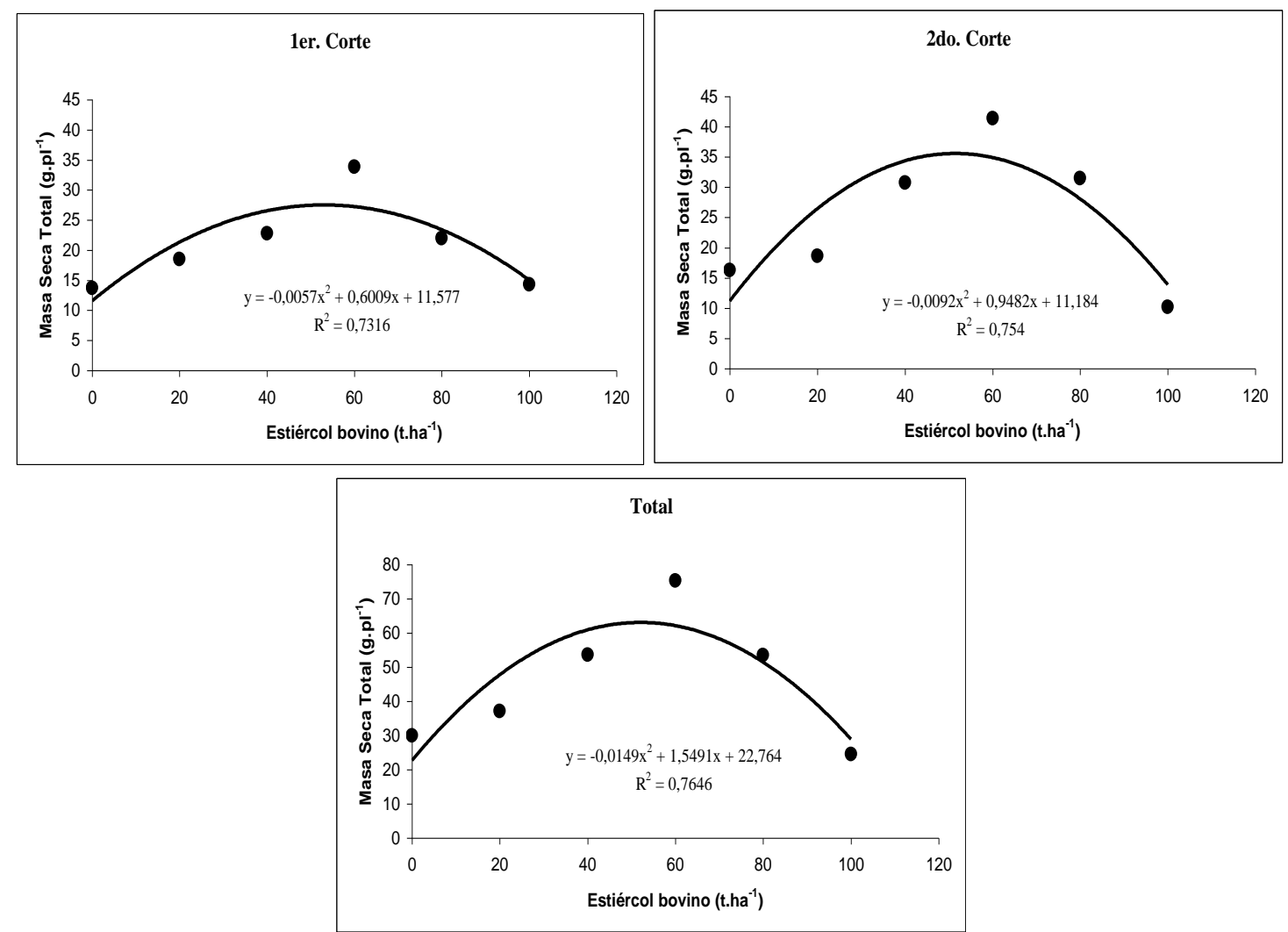

Figura 3. Curvas ajustadas entre las medias de la masa seca total de Stevia por planta $\left(\mathrm{g} \mathrm{pl}^{-1}\right)$ y las dosis de estiércol bovino aplicadas. Pedro Juan Caballero, Paraguay, 2008.

En la Tabla 5 se presentan las medias del rendimiento en MST de Stevia $\left(\mathrm{kg} \mathrm{ha}^{-1}\right)$ por efecto de las diferentes dosis de estiércol bovino aplicado, donde se constata que en el primer corte, la dosis correspondiente a $60 \mathrm{t} \mathrm{ha}^{-1} \mathrm{de}$ estiércol bovino, permitió el mayor rendimiento en MST de Stevia con un promedio de $2760,83 \mathrm{~kg} \mathrm{ha}^{-1}$. En el segundo corte, con las dosis de 40 y $60 \mathrm{t} \mathrm{ha}^{-1}$, se obtuvieron los mejores rendimientos de MST (2521,66 y $2272,50 \mathrm{~kg} \mathrm{ha}^{-1}$ ). Estos a la vez fueron semejantes entre si estadísticamente y superiores a las demás dosis: 20, 80, $100 \mathrm{t} \mathrm{ha}^{-1} \mathrm{y}$ sin aplicación de estiércol bovino. 
Tabla 5. Medias del rendimiento en masa seca total de Stevia $\left(\mathrm{kg} \mathrm{ha}^{-1}\right)$ por efecto de los tratamientos. Pedro Juan Caballero, Paraguay.

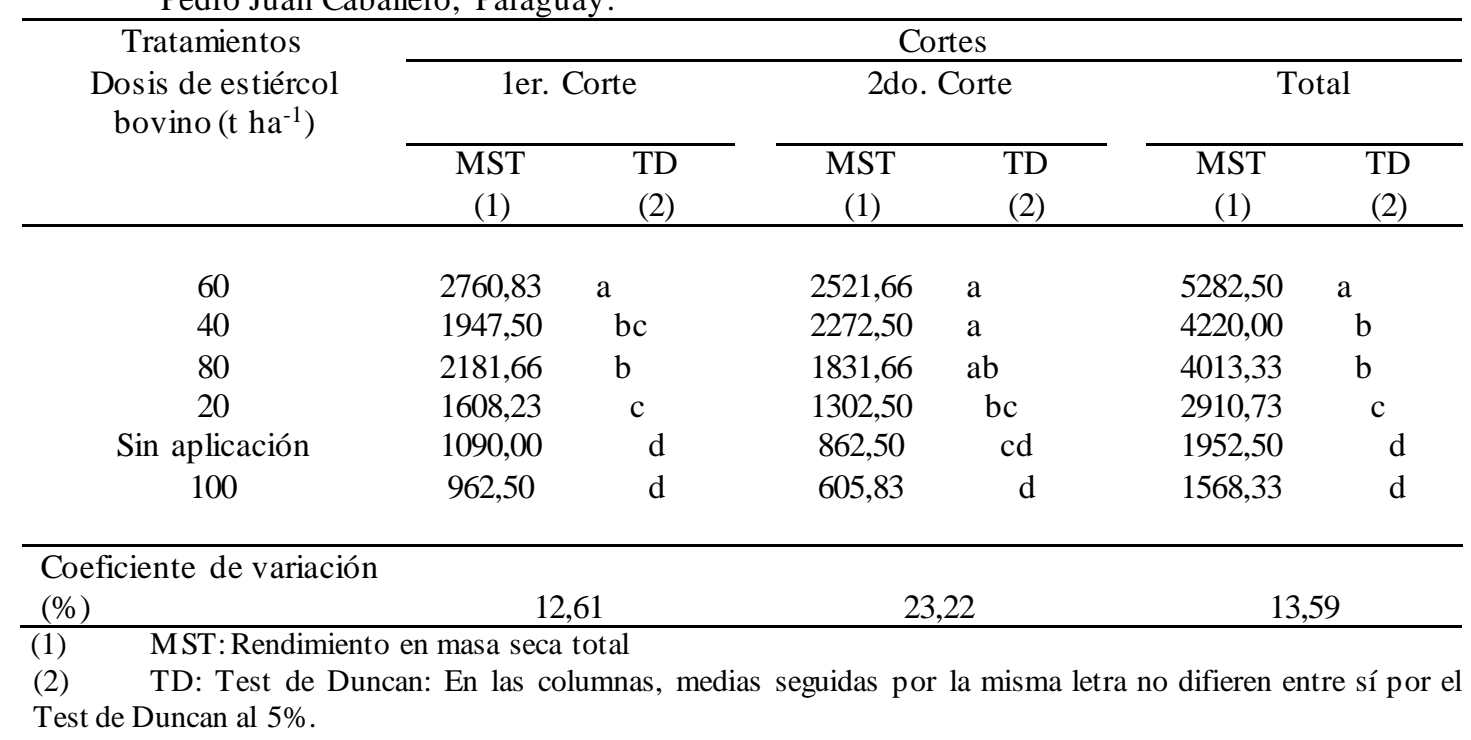

En trabajos realizados en Colombia donde se evaluaron masa seca total, rendimiento, altura de planta, diámetro de tallo de Stevia no han verificado diferencias significativas entre la fertilización química y orgánica con germicompost y gallinaza, siendo los rendimientos de 4700, 3900 y $7700 \mathrm{~kg} \mathrm{ha}^{-1}$, para las dosis de 200, $250 \mathrm{y}$ $300 \mathrm{~kg} \mathrm{ha}^{-1}$ de gallinaza respectivamente (Daza et al. 2015)

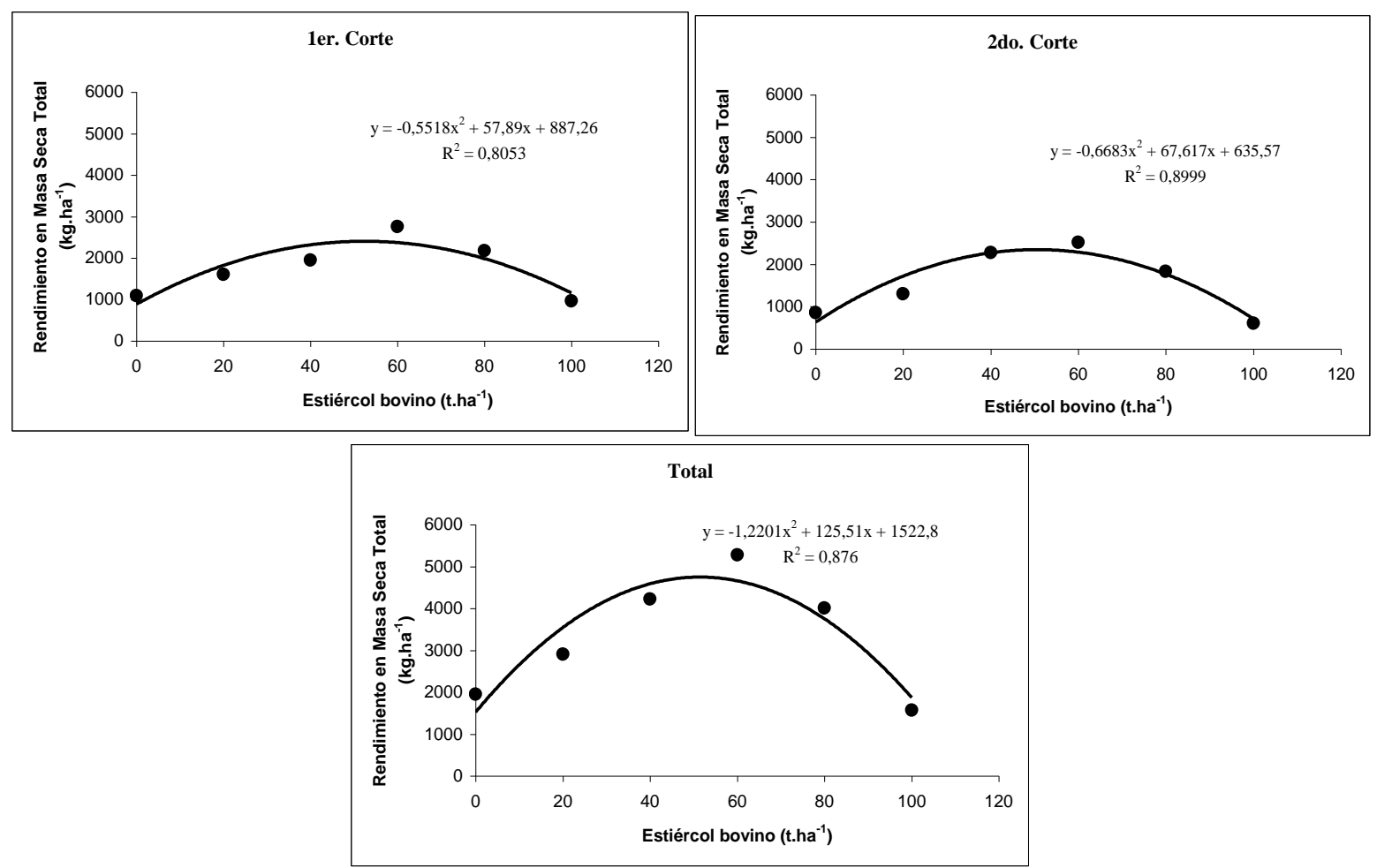

Figura 4. Curvas ajustadas entre las medias del rendimiento en masa seca total de Stevia $\left(\mathrm{kg} \mathrm{ha}^{-1}\right)$ y las dosis de estiércol bovino aplicadas. Pedro Juan Caballero, Paraguay, 2008. 
Los valores críticos de máxima eficiencia técnica para el rendimiento en MST corresponden a 52,45; 50,58 y 51,43 $\mathrm{t}$ ha ${ }^{-1}$, con los que se alcanzarían rendimientos teóricos de MST de Stevia equivalentes a 2405,58; 2345,90 y $4750,56 \mathrm{~kg} \mathrm{ha}^{-1}$, respectivamente, para el primer corte, segundo corte y en forma total (Figura 4).

En relación a las variables MSH y MST, Bonilla, Sánchez y Perlaza (2007) obtuvieron los mejores resultados: 433,3 y $320 \mathrm{~kg} \mathrm{ha}^{-1}$ en el primer corte de uniformización a los 45 días y segundo corte a los 45 días después del primer corte, respectivamente, cuando se aplicó $100 \mathrm{~kg} \mathrm{ha}^{-1}$ de gallinaza en el cultivo de Stevia. La MST obtenida fue de 1102,1 y 755,6 $\mathrm{kg} \mathrm{ha}^{-1}$, valores inferiores a los obtenidos en este experimento.

En cuanto a la distribución de asimilados por planta, los valores promedios para ambos cortes se presentan en la Tabla 6. En el primer corte, todos los tratamientos permitieron la distribución de asimilados estadísticamente semejantes entre sí, con una media de $73,88 \%$ a hojas y $26,10 \%$ a tallos. Para el segundo corte, se observó que la mayor distribución de MSH por planta, se obtuvo con la aplicación de 100 y $20 \mathrm{t} \mathrm{ha}^{-1}$ e incluso con el testigo sin aplicación de estiércol bovino con valores promedios estadísticamente similares entre sí de 78,32; 73,71; y $72,61 \%$ de asimilados a las hojas. Mientras que la cantidad de asimilados en tallos fueron similares para la mayoría de los tratamientos y el testigo a excepción de la aplicación de $100 \mathrm{t} \mathrm{ha}^{-1}$, el testigo y $20 \mathrm{t} \mathrm{ha}^{-1}$ que presentaron una menor distribución de asimilados, con 21,67; 26,29 y 27,38\%. Probablemente el efecto del bajo contenido de materia orgánica en el testigo, que no recibió estiércol bovino, y con la aplicación de $20 \mathrm{t} \mathrm{ha}^{-1}$ y por otro lado un efecto de sobredosis en las plantas de Stevia que recibieron la aplicación de $100 \mathrm{tha}^{-1}$.

Tabla 6. Medias de la distribución de asimilados por planta (\%) por efecto de los tratamientos. Pedro Juan Caballero, Paraguay.

\begin{tabular}{|c|c|c|c|c|c|c|c|c|}
\hline \multirow{3}{*}{$\begin{array}{c}\text { Tratamientos } \\
\text { Dosis de estiércol } \\
\text { bovino }\left(\mathrm{t} \mathrm{ha}^{-1}\right)\end{array}$} & \multicolumn{8}{|c|}{ Cortes } \\
\hline & \multicolumn{4}{|c|}{ 1er Corte } & \multicolumn{4}{|c|}{ 2do. Corte } \\
\hline & $\begin{array}{c}\mathrm{AH} \\
(2) \\
\end{array}$ & $\begin{array}{l}\text { TD } \\
(4) \\
\end{array}$ & $\begin{array}{l}\text { AT } \\
\text { (3) }\end{array}$ & $\begin{array}{l}\text { TD } \\
(4) \\
\end{array}$ & $\begin{array}{l}\mathrm{AH} \\
(2) \\
\end{array}$ & $\begin{array}{l}\text { TD } \\
(4) \\
\end{array}$ & $\begin{array}{l}\mathrm{AT} \\
(3) \\
\end{array}$ & $\begin{array}{l}\text { TD } \\
(4) \\
\end{array}$ \\
\hline 60 & 73,45 & $\mathrm{a}$ & 26,54 & $\mathrm{a}$ & 70,64 & $\mathrm{~b}$ & 29,36 & $\mathrm{a}$ \\
\hline 40 & 73,35 & $\mathrm{a}$ & 26,64 & $\mathrm{a}$ & 68,68 & $\mathrm{~b}$ & 31,31 & $\mathrm{a}$ \\
\hline 80 & 72,42 & $\mathrm{a}$ & 27,57 & $\mathrm{a}$ & 70,92 & $\mathrm{~b}$ & 29,08 & $\mathrm{a}$ \\
\hline 20 & 72,85 & $\mathrm{a}$ & 27,14 & $\mathrm{a}$ & 72,61 & $a b$ & 27,38 & $a b$ \\
\hline 100 & 74,34 & $\mathrm{a}$ & 25,65 & $\mathrm{a}$ & 78,32 & $\mathrm{a}$ & 21,67 & $\mathrm{~b}$ \\
\hline Sin aplicación & 76,89 & $\mathrm{a}$ & 23,10 & $\mathrm{a}$ & 73,71 & $a b$ & 26,29 & $a b$ \\
\hline $\begin{array}{l}\text { Coeficiente de } \\
\text { variación }(\%)\end{array}$ & \multicolumn{2}{|c|}{3,67} & \multicolumn{2}{|c|}{5,16} & & & \multicolumn{2}{|c|}{13,60} \\
\hline
\end{tabular}

(2) AH: Asimilados a hojas (\%)

(3) At: Asimilados a tallos (\%)

(4)TD: Test de Duncan: En las columnas, medias seguidas por la misma letra no difieren entre sí por el Test de Duncan al $5 \%$.

En relación a la variable distribución de asimilados a las hojas observado en este trabajo para el primer y segundo cortes son superiores a lo señalado por Jarma et al. (2006) quienes indican que la distribución de asimilados a las hojas para el cultivo de Stevia es de $60 \%$.

\section{CONCLUSIONES}

Las dosis de estiércol bovino aplicados influyen sobre la acumulación de masa seca de hojas y tallos de plantas de Stevia rebaudiana (Bertoni) Bertoni bajo irrigación.
Con la aplicación de 60,0 t ha- $\mathrm{ha}^{-1}$ de estiércol bovino se obtienen los mejores rendimientos en masa seca de hojas y tallos por planta en el primer, segundo periodo de corte y en forma total.

La aplicación de estiércol bovino en las dosis utilizadas influye en la distribución de asimilados en plantas de Stevia rebaudiana (Bertoni) Bertoni irrigadas en el segundo periodo de corte. 


\section{REFERENCIAS BIBLIOGRAFICAS}

Bonilla, CR; Sánchez, MS; Perlaza, DF. 2007. Evaluación de métodos de propagación, fertilización nitrogenada y fenología de estevia en condiciones del Valle del Cauca. Acta Agronómica. 56(3): 131-134.

Casaccia, J; Álvarez, E. 2006. Recomendaciones técnicas para una producción sustentable del ka'ahe'e [Stevia rebaudiana (Bertoni) Bertoni] en el Paraguay. , Caacupé, MAG, 51 p. (Manual técnico ${ }^{\circ}$. 8)

Daza, MC; Díaz, J; Aguirre, E; Urrutia, N. 2015. Effect of slow-release fertilizers on nitrate leaching and nitrogen nutrition in stevia. Revista Colombiana de Ciencias Hortícolas 9(1): 112-123.

DINAC (Dirección Nacional de Aeronáutica Civil, Paraguay) 2012. Boletín climatológico (en línea). Asuncion, Paraguay, DINAC. Consultado 20 abr. 2015. Disponible en www.meteorologia.gov.py/ publicaciones.php

Duarte, RC. 2008. Anális is de la producción del ka’a he’e (en línea). Paraguay, AFD. Consultado 20 mar. 2015. Disponible en www.mag.gov.py/KAA\%20HEE.pdf

Encina, A. 2008. Condiciones ideales para el cultivo (en línea). Italia, NLI. Consultado 12 ago 2016. Disponible en http://www.Ini.unipi.it/stevia/Suppl emento\%20/PAG39006.htm

Jarma, A; Rengifo, T; Aramendiz-Tatis, H. 2006. Fisiología de estevia (Stevia rebaudiana) en función de la radiación en el Caribe colombiano: II: Análisis de crecimiento. Agronomía Colombiana 24(1): 38-47.

López, L; Peña, L. 2004. Plan estratégico para la creación de una em-presa dedicada a la producción y comercialización de edulcorante a base de stevia. Tesis Ing. Bogota, Colombia, Pontificia Universidad Javeriana, Facultad de Ingeniería. 125 p.
Lozano, CMG; Ramírez, JG. 2015. Producción de Stevia rebaudiana Bertoni, con abonos orgánicos y biofertilizantes. Paquete tecnológico. Centro de Investigación Regional Sureste. (en línea). INIFAP. Consultado el 25 jul. 2016. Disponible en http://www.bioenergeticos.gob.mx/wpcontent/uploads/2016/02/publication-stevia.pdf.

Liu, X; Ren, G; Shi, Y. 2011. The effect of organic manure and chemical fertilizer on growth and development of Stevia rebaudiana Bertoni. Energy Procedia 5: 1200-1204.

Mejía, F. 2009. Desarrollo económico de la stevia para comunidades y futuras empresas: cultivos orgánicos: Barbosa Antioquia Colombia (en línea). Colombia, Cooprodestevia. Consultado 20 mar. 2016. Disponible en www.cooprodestevia.blogspot.com.

Serfaty, M; Ibdah, M; Fischer, R; Chaimovitsh, D; Saranga, Y; Dudai, N. 2013. Dynamics of yield components and stevioside production in Stevia rebaudianagrown under different planting times, plant strands and harvest regime. Industrial Crops and Products 50:731-736.

Yong-Heng, Y; Su-Zhen, H; Yu-Lin, H; Hai-Yan Y; Chun-Sun, G. 2014. Base substitution mutations in uridinediphosphate - dependent glycosyltransferase $76 \mathrm{Gl}$ gene of Stevia rebaudiana causes the low levels of rebaudioside: A Mutations in UGT76G1: A key gene of steviol glycosides synthesis. Plant Physiol Biochem 80: 220-225. 